\title{
Reactivities Involved in the Regioselectivity of Osazone Formation
}

\author{
Francisco Sánchez-Viesca*, Reina Gómez G \\ Department of Organic Chemistry, Faculty of Chemistry, National Autonomous University of Mexico, Mexico City (CDMX), Mexico \\ *Corresponding author: franviesca@yahoo.com
}

\begin{abstract}
The mechanism of osazone formation has been subject of many studies during a vast period of time. However, the regiochemistry related to osazones remained an unsolved problem until recently that we presented our theoretical findings that explain the factors that direct the regiochemistry of osazone formation. Now, we wish present to the teaching community this subject, as well as a discussion of an example of mixed osazone formation. This new topic includes the factors that conduce to the main product. This communication will fill a gap existing in the Organic Chemistry textbooks.
\end{abstract}

Keywords: fructosazone, hydrogen bonds, 1,4-Hydrogen transfer, internal oxido-reduction, leaving groups, Lewis bases

Cite This Article: Francisco Sánchez-Viesca, and Reina Gómez G, "Reactivities Involved in the Regioselectivity of Osazone Formation." World Journal of Organic Chemistry, vol. 5, no. 1 (2017): 11-16. doi: 10.12691/wjoc-5-1-3.

\section{Introduction}

An aldose reacts with three equivalents of phenylhydrazine, forming a vicinal bis-phenylhydrazone, the osazone. With a ketose, having two alpha positions, there are hypothetically two reaction sites. However, fructose with a keto group at $\mathrm{C}-2$ only reacts at $\mathrm{C}-1$ and $\mathrm{C}-2$, not at $\mathrm{C}-2, \mathrm{C}-3$. This regioselectivity has not been explained until recently in two academic communications $[1,2]$.

Now we present to the students a shorter and more accessible version on this subject.

The paper is centered in the regioselective rearrangement of fructose phenylhydrazone to 2-deoxy-2-phenylhydrazinoD-glucose. This key intermediate forms glucosazone after several steps.

A new topic in included, the discussion of an example of mixed osazone formation, pointing out the factors that conduce to the yields of the obtained products, i.e., to the main and the secondary product.

\section{Experimental Facts and Theories}

The first compound formed in the reaction of an $\alpha$-hydroxycarbonyl compound with phenylhydrazine is the phenylhydrazone. In order that the reaction may proceed and form a second phenylhydrazone, there must be an oxidation of the vicinal hydroxy group.

At first it was believed that this oxidation step was accomplished by means of the remaining phenylhydrazine molecules. However, this point of view was discarded because phenylhydrazine has not oxidizing properties [3].

Later, Weygand in Germany pointed out that this oxidation step can be explained as a variant of the Amadori rearrangement [4]. The original reaction takes place between an aldose and ammonia or an amine [5]. The reaction does not stop in the first formed imino derivative, but proceeds by prototropy to the 1-amino-1deoxy-ketose, Figure 1.

With a ketose the reaction is indicated in Figure 2.

This rearrangement was observed for the first time by Heyns [6,7], and is known as the Heyns rearrangement and also as the retro-Amadori rearrangement. He employed fructose and $10 \% \mathrm{NH}_{4} \mathrm{OH}$, as well as liquid ammonia.<smiles>[R]C(O)C=O</smiles><smiles>[R]NCCC</smiles><smiles>[R]N1CC[C@H](CC)[C@H]([2H])O1</smiles>
aldimine<smiles>[R]NCC([R])=O</smiles>

Figure 1. Amadori rearrangement 
With a ketose the reaction would be:<smiles>[R]C(=O)CO</smiles>

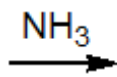<smiles>[R]C1CCCC1C(O)C1CCN1</smiles><smiles>[R]C(C)(N)/C=C\CCCO</smiles><smiles>[R]C(N)C=O</smiles>

\section{D-glucosamine}

Figure 2. Heyns or retro-Amadori rearrangement

However, this reaction mechanism does not explain why the ketose reacts with the hydroxymethyl group or methylol (C-1), and not with the hydroxymethylene group at C-3.

Weygand proposed two routes [8,9], A and B, in order to explain osazone formation in carbohydrates. These routes are also mentioned in references $[10,11]$.

First, we will center our attention in route A, Figure 3, and not with aldoses but with ketoses, since we are interested in fructosazone. Moreover, ulterior experiments by Russian researchers are in accord with route A for fructosazone formation.
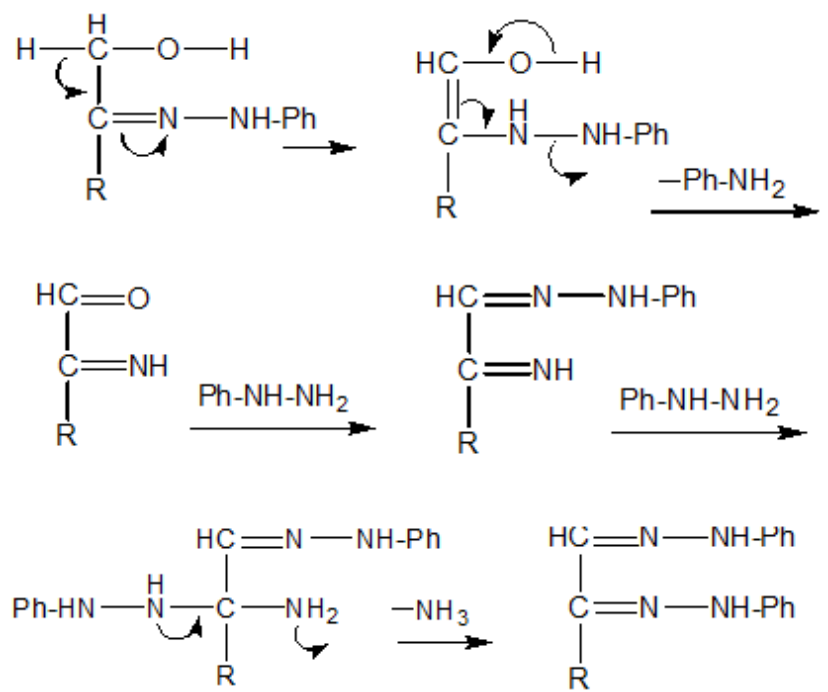

Figure 3. Weygand's route A<smiles>[R]C1CCCC1OPNc1ccccc1</smiles><smiles>CCCCC</smiles>

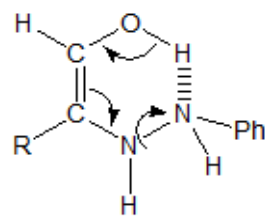<smiles>[R]C(=N)C=O</smiles>

Figure 4. Proposed via of aniline elimination
The split of aniline from a ketose phenylhydrazone in the above sequence has been explained, after enolization, via a six-member concerted reaction mechanism [12], Figure 4.

However, this point of view is dubious due to the low basicity of the $\alpha$-nitrogen because the electron pair in this nitrogen is distributed by resonance over the aromatic ring and thus is less available (valence-bond formulation). According to molecular-orbital theory, the unshared electron pair in the $\alpha$-nitrogen is in a p-orbital that overlaps with the benzene $\pi$-orbital system, thus reducing the nitrogen basicity. That nitrogen reacts only with strong acids.

Years later than Weygand's proposals appeared two interesting papers, one in the United States and the other in Russia, [13,14]. Both groups used two different aryl hydrazines for osazone formation. This was done with the purpose to know to which of the Weygand's routes the experiment was in accord in each case.

Wright [13] studied the reaction of D-mannose phenylhydrazone with p-bromophenylhydrazine. The resulting intermediate splits out p-bromoaniline and aniline, in a ratio 70:30. This is in agreement with Weygand's route $B$, Figure 5, i.e., the existence in this case of a mixed ene-bishydrazine as intermediate, Figure 6.<smiles>[R]C(O)/C=N\Nc1ccccc1</smiles><smiles>[R]/C(O)=C/NNc1ccccc1</smiles><smiles>[R]C(=O)CNNc1ccccc1</smiles><smiles>[R]C(CNc1ccccc1)=NNc1ccccc1</smiles><smiles>[R]/C(C=N)=N/[PH2+][PH2+]N</smiles>
$=\mathrm{N}-\mathrm{NH}-\mathrm{Ph}+\mathrm{Ph}-\mathrm{NH}_{2}$<smiles>[R]C(=N)/C=N\Nc1ccccc1</smiles>

Ph-NH-NH ${ }_{2}$<smiles>[R]C(/C=N\Nc1ccccc1)=N/Nc1ccccc1</smiles>

Figure 5. Weygand's route B 


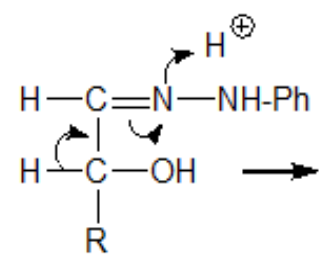<smiles>[R]C(=O)CNNc1ccccc1</smiles>

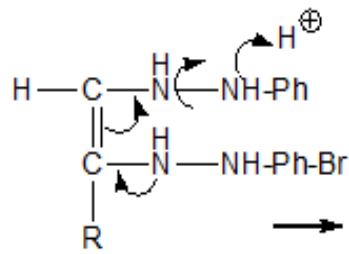

\section{Br-Ph-NH-NH ${ }_{2}$}

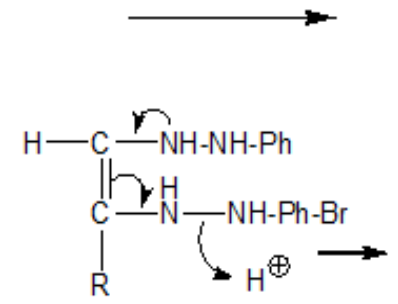

\section{$\mathrm{Br}-\mathrm{Ph}-\mathrm{NH}-\mathrm{NH}_{2}$}<smiles></smiles><smiles></smiles>

Figure 6. Formation of a dibromo osazone and a mixed osazone via acid catalysis

However, the experimental ratio of p-bromoaniline and aniline (70/30) has not been explained and will be discussed later in the next section.

Shemyakin and coworkers [14] performed a study with the use of ${ }^{15} \mathrm{~N}$ and two aryl hydrazines. They heated D-fructose- $\beta-{ }^{15} \mathrm{~N}$-p-nitrophenylhydrazone and ordinary phenylhydrazine in acetic acid in the presence of acetic anhydride. They found formation in quantitative yield of unlabelled p-nitroacetanilide and ammonia containing almost the entire initial ${ }^{15} \mathrm{~N}$, Figure 7 . These results are in accordance with Weygand's route A. See previous flow diagram.<smiles>[R]C(CO)=[N+]([O-])N[SH](=O)[O-]</smiles><smiles>[R]/C(=C/O)[NH2+]NS(=O)(=O)[O-]</smiles><smiles>[R]C(C)=[NH+][NH2+][PH2+]</smiles>
$\mathrm{CH}_{3}-\mathrm{CO}-\mathrm{NH}-\mathrm{Ph}-\mathrm{NO}_{2}$

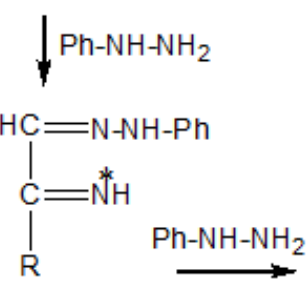

Figure 7. Shemyakin's experiment with ${ }^{15} \mathrm{~N}\left(\mathrm{~N}^{*}\right)$

The regioselectivity observed in fructosazone formation was not considered in all the papers related to osazone chemistry and therefore it is not necessary cite them.

\section{Discussion}

Fructose gives an osazone at $\mathrm{C}-1, \mathrm{C}-2$. But, being the carbonyl group at $\mathrm{C}-2$, why an osazone at $\mathrm{C}-2, \mathrm{C}-3$ is not formed? This regioselectivity not only has not been explained by other authors, the problem has been overlooked.

We provide a reaction mechanism that explains the observed regiochemistry. Our proposal is based in very well known reactivities and in related reactions, as we will see.

It is established that the reaction of an $\alpha$-hydroxycarbonyl compound (an $\alpha$-ketol) and an arylhydrazine gives the arylhydrazone. The problem is why in the fructosazone formation the reaction proceeds to $\mathrm{C}-1$ and not to $\mathrm{C}-3$. At this step, the only existing difference is that at $\mathrm{C}-1$ there is a primary alcohol, and at $\mathrm{C}-3$ there is a secondary one. Their respective reactivities are: in acidic medium, the secondary alcohol can be dehydrated more easily than a primary one; but, in the presence of a base, a primary alcohol is more reactive than a secondary one $[15,16]$. Thus, the greater acidity of the primary alcohol in the hydroxymethyl group (C-1) must be the determinant factor in the next step. Both hydroxy groups, at $\mathrm{C}-1$ and at $\mathrm{C}-3$, can form a hydrogen bond with the arylhydrazone $\beta$ nitrogen. However, from these two possibilities, the hydrogen bond with the primary alcohol at C-1 is preferred because this $\mathrm{OH}$ is a better hydrogen donor due to its greater acidity, Figure 8. 
<smiles>OCC(=NNc1ccccc1)C(O)C(O)C(O)CO</smiles>

Figure 8. Two possibilities of hydrogen bond formation in fructose phenylhydrazone. The second is the preferred one

It is well known that nitrogen can react as an organic base (a Lewis base); so, besides forming a five member secondary ring, it can promote an internal oxido-reduction, via a cyclic concerted-mechanism (internal catalysis) Figure 9.

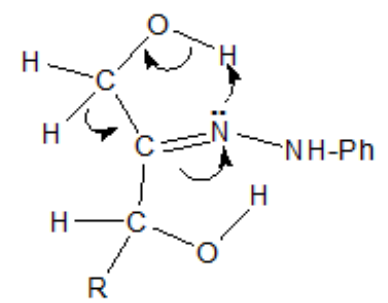<smiles>[R]C(O)C(C=O)(C=O)NNc1ccccc1</smiles>

Figure 9. Concerted oxido-reduction step in fructose phenylhydrazone

The required driving force can be coming from the hot solvent (thermal rearrangement). Cf. Shemyakin [14].

This experimental fact supports our theory that no catalyst intervene in this step of osazone formation. The autocatalysis is independent of an external medium (when $\mathrm{AcOH}$ is used) because internal factors are immediate and predominate over external ones.

In our case the five-member ring is preferred to a six-member one because the $\mathrm{C}=\mathrm{N}$ group yields to the $\beta$-nitrogen in the phenylhydrazone a $\delta^{-}$charge. On the contrary, there is a $\delta^{+}$in the $\alpha$-nitrogen because its electron pair is in a p-orbital that overlaps with the benzene $\pi$-orbital system, thus lowering the nitrogen basicity (MO theory). According to valence-bond formulation, the electron pair on the $\alpha$-nitrogen is distributed over the aromatic ring, thus diminishing its availability. On the other hand, a six-member ring does not favour a concerted reaction mechanism.

Examples of 1,2-alkyl migration, with concomitant 1,4-hydrogen transfer, have been reported in $\alpha$-hydroxy imines [17], Figure 10. These reactions, although different, are in line with our proposed reaction mechanism.
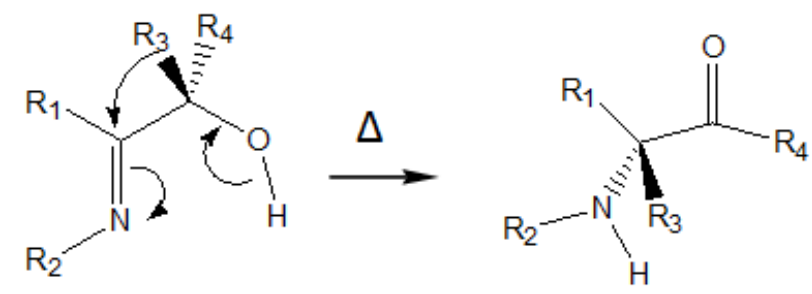

Figure 10. Thermal rearrangement of $\alpha$-hydroxy imines
The intermediate resulting from our oxido-reduction step, a 2-hydrazino-2-deoxy aldose, Figure 9, is not the imino aldehyde proposed in Weygand's route A, Figure 3. This difference is expected since we have taken into account the regioselectivity that occurs in this process and in Weygand's mechanism this is not considered. However, after two steps, both sequences arrive to the same intermediate, i.e., the 2-iminophenylhydrazone, Figure 11, then, reaction with other phenylhydrazine molecule leads to an aminal. Finally, loss of ammonia gives the osazone.<smiles>[R]C(O)C(C=O)(NN)NNc1ccccc1</smiles>

\section{2-deoxy-2-hydrazino aldose}

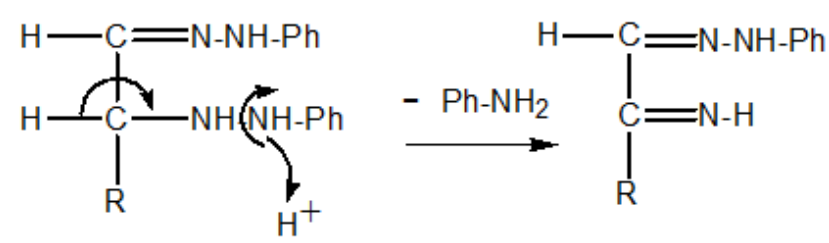<smiles>[R]C(/C=N/Nc1ccccc1)=N/Nc1ccccc1</smiles>

Figure 11. Last steps of fructosazone formation, they agree with Shemyakin's experiment
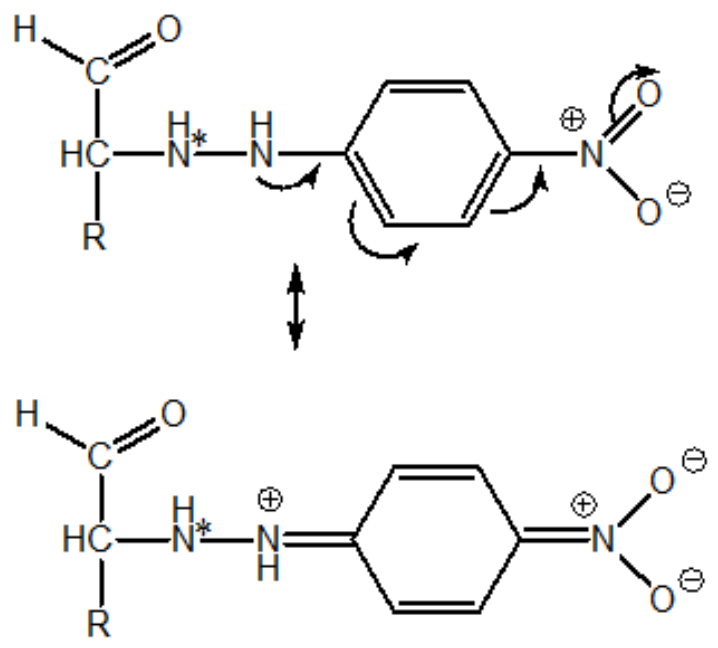

Figure 12. Intermediate and nitronate resonance structure 
According with our oxidation-reduction proposal, in the case of Shemyakin's experiment, Figure 7, the resulting intermediate would be the one indicated in Figure 12. In this molecule, the elimination of p-nitroaniline via acid catalysis is not probable due to the very weak basicity of the $\alpha$-nitrogen which is involved in resonance. However, the keto-enol tautomerism favours the elimination of p-nitroaniline, as an anion with a quinone di-imine structure, Figure 13.

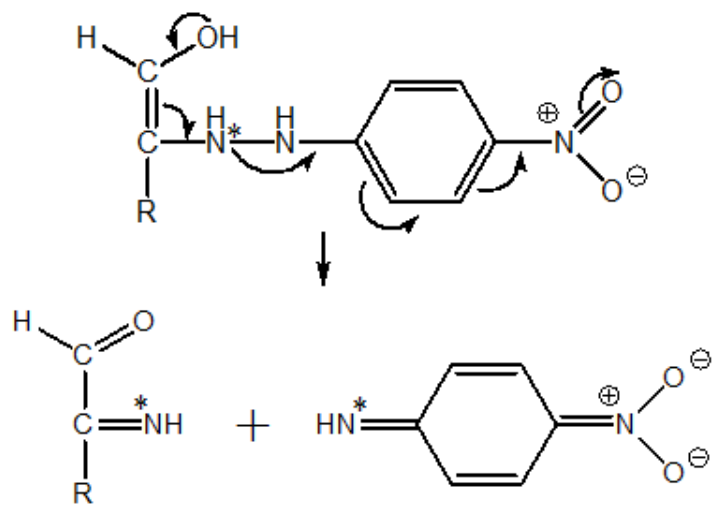

Figure 13. Fast elimination of p-nitroaniline as a nitronate anion

Now let's turn our attention to the example of mixed osazone formation mentioned in the previous section. Figure 6 shows the formation of a dibromo osazone and a mixed osazone via acid catalysis.

In the mixed ene-bis-hydrazine, the $\alpha$-nitrogen in the aniline fragment is more basic than the other $\alpha$-nitrogen in this molecule. This can be deduced since aniline $(\mathrm{pKa}=4.60)$ is more basic than $\mathrm{p}$-bromoaniline $(\mathrm{pKa}=3.86)$ [18]. Figure 6 shows the preferred protonation in the ene-bis-hydrazine, i.e., in the aniline segment. This protonation would favour a ratio aniline/p-bromoaniline. But the experimental ratio is the opposite: $p$-bromoaniline/aniline, $70 / 30$. Thus, this step must be an internal process without acid catalysis; the enamine reactivity and the leaving group being of utmost importance, as we will see.

In the mixed ene-bis-phenylhydrazine, the inductive effect of the bromine atom is transmitted to the end of the $\pi$-system creating a $\delta^{+}$at the $\alpha$-nitrogen since the p-orbital of $\mathrm{Br}$ and $\mathrm{N}$ are both involved in the $\pi$-system (long distance effect), Figure 14.

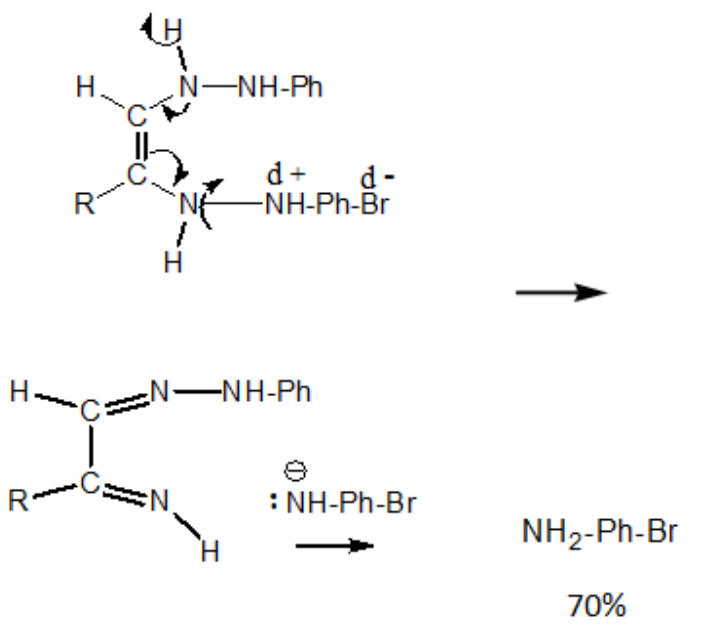

Figure 14. Formation of p-bromoaniline as main product via an internal mechanism through a vinylene bridge
The electron donor effect of the enamine vicinal to the anilino group, combined with the $\delta^{+}$in the p-bromoaniline fragment, can form a phenylhydrazone at $\mathrm{C}-1$ and an imino group at $\mathrm{C}-2$, with the concomitant elimination of a good leaving group, since the negative charge is in the nitrogen with a previous $\delta^{+}$, as indicated in Figure 14.

On the other hand, the $\delta^{+}$at the $\alpha$-nitrogen decreases the reactivity of the vicinal enamine group since the formation of an adjacent positive charge is hampered or unfavourable, leading to the secondary product, Figure 15.

The ketimino hydrazone and aldimino hydrazone above formed react as indicated in Figure 16, yielding two different osazones.

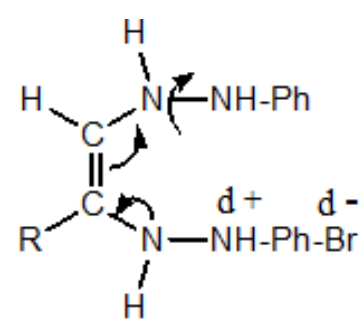<smiles>[R]/C(=N/N[Pb])[C@H](C)/N=C\[OH2+]</smiles>

Figure 15. Formation of aniline as secondary product

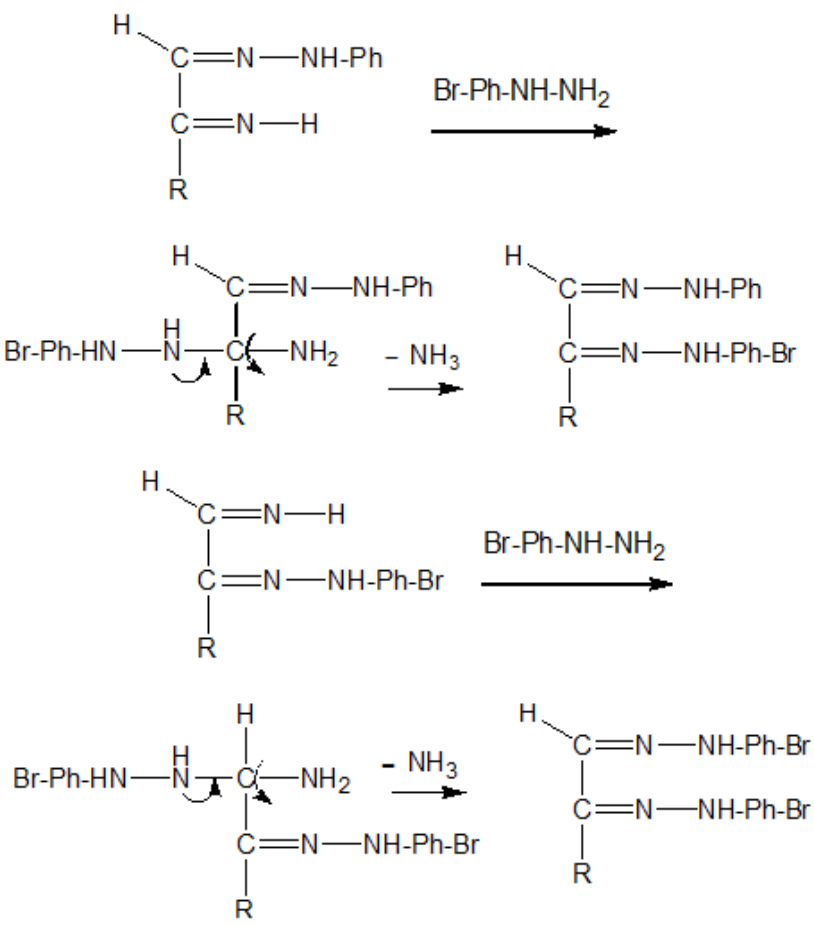

Figure 16. Formation of the monobromo- and the dibromo osazone

\section{Conclusions}

We have found that the regiochemistry in fructosazone is established in the oxido-reduction that occurs at C-1, C2 , after the phenylhydrazone is formed. 
The different acidity between a primary and a secondary alcohol is favourable, or not, to hydrogen bond formation and subsequent reactions in the phenylhydrazone molecule.

The oxido-reduction step has now been explained as a 1,4-hydrogen transfer via a cyclic, concerted five-member reaction mechanism (internal catalysis).

The above point of view was substantiated with cognate examples of $\alpha$-hydroxy imines chemical deportment.

The intermediate resulting from the oxido-reduction rearrangement, after two steps, is in accordance with Shemyakin's experimental results.

When D-mannose phenylhydrazone reacted with $\mathrm{p}$ bromophenylhydrazine, p-bromoaniline and aniline were formed in a 70/30 ratio, respectively. Since acid catalysis would yield aniline as the main product, we found a reaction mechanism that explains the experimental results.

The reactivities involved in the proposed internal process are: an electrical factor, enamine reactivity and the preferred leaving group.

This type of theoretical analysis is seldom achieved.

\section{References}

[1] Sánchez-Viesca, F. and Gómez, R., "On the regiochemistry in the Heyns rearrangement", Am. J. Chem., 5(3), 86-89, 2015.

[2] Sánchez-Viesca, F. and Gómez, R., "On fructosazone regiochemistry", Modern Chemistry, 4(1), 1.5, 2016.

[3] Packer, J. and Vaughan, J., A Modern Approach to Organic Chemistry, Clarendon Press, Oxford, U. K., 1958, 479-482.

[4] Weygand, F., "Amadori Umlagerungen", Ber., 73(11), 1259-1278, 1940; Chem. Abstr., vol. 35, 3234-3235, 1941.
[5] Wrodnigg, T. M. and Eder, B., "The Amadori and Heyns rearrangements", Top. Curr. Chem., 215, 115-152, 2001.

[6] Heyns, K. and Koch, W., "Formation of an amino sugar from Dfructose and ammonia", Z. Naturforsch., 7b, 486-488, 1952; Chem. Abstr., vol. 47, 3392f, 1953.

[7] Heyns, K. and Meinecke, K. H., "Über Bildung und Darstellung von d-Glucosamin aus Fructose und Ammoniak", Chem. Ber., 86(11), 1453-1462, 1953; Chem. Abstr., vol. 49, 2333d, 1955.

[8] Weygand, F., "Theorie der Osazonbildung", Ber., 73(11), 12841291, 1940; Chem. Abstr., vol. 35, 3235, 1941.

[9] Weygand, F. and Reckhaus, M., "Zur Theorie der Osazonbildung", Chem. Ber., 82(4-5), 438-442, 1949; Chem. Abstr., vol. 44, 19111912, 1950.

[10] Percival, E. G. V., "The structure and reactivity of the hydrazone and osazone derivatives of the sugars", Adv. Carbohydr. Chem., 3 , 23-44, 1948.

[11] Hassner, A. and Catsoulacos, P., "On the mechanism of osazone formation", Tetrahedron Lett., No.6, 489-493, 1967.

[12] Metha, B. and Metha, M., Organic Chemistry, Prentice-Hall of India, 2005, 939.

[13] Sears, C. and Wright, J. C., "The use of p-bromophenylhydrazine to determine the mechanism of osazone formation", Proc. West Virginia Acad. Sci., 33, 78-80, 1961; Chem. Abstr., vol. 56, $10254 \mathrm{~g}, 1962$

[14] Shemyakin, M. M., Maimind, V. J., Ermolaev, K. M. and Bamdas, E. M., "The mechanism of osazone formation", Tetrahedron, 21 , 2771-2777, 1965

[15] McMurry, J., Quimica Orgánica, 8th. ed., Cengage Learning, Mexico, 2012, Apéndice B, Constantes de acidez, p. A-9.

[16] Migrdichian, V., Organic Synthesis, Reinhold, New York, 1960, vol. I, 16

[17] Compain, Ph., Gore, J. and Vatele, J. M., "Rearrangement of $\alpha$-hydroxy imines to $\alpha$-amino ketones: Mechanistic aspects and synthetic applications", Tetrahedron, 52(19), 6647-6664, 1996.

[18] Rappoport, Z., Ed., Handbook of tables for Organic Compound Identification, 3rd. ed., Chemical Rubber, Cleveland, 1967, 436-437. 